\title{
Silylated Thiol-Containing Cellulose Nanofibers as a Bio-Based Flocculation Agent for Ultrafine Mineral Particles of Chalcopyrite and Pyrite
}

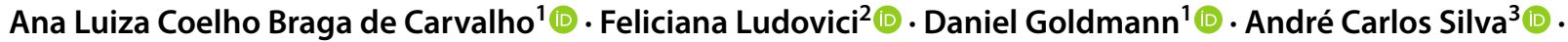 \\ Henrikki Liimatainen ${ }^{2}$ (1)
}

Received: 9 March 2021 / Accepted: 6 September 2021 / Published online: 21 September 2021

(c) The Author(s) 2021

\begin{abstract}
A considerable amount of very fine particles can be found, e.g., stored in tailing ponds, and they can include valuable or hazardous minerals that have the potential to be recovered. Selective flocculation, i.e., the formation of larger aggregates from specific minerals, offers a promising approach to improve the recovery of ultrafine particles. This study focuses on the use of a new bio-based flocculation agent made of silylated cellulose nanofibers containing a thiol-functional moiety (SiCNF). Flocculation was performed in separated systems of ultrafine mineral dispersions of pyrite, chalcopyrite, and quartz in aqueous alkaline medium. The flocculation performance of SiCNF was addressed in terms of the turbidity reduction of mineral dispersions and the floc size, and the results were compared with the performance of a commercial anionic polyacrylamide. SiCNF exhibited a turbidity removal efficiency of approximately $90 \%-99 \%$ at a concentration of 4000-8000 ppm with chalcopyrite and pyrite, whereas the turbidity removal of quartz suspension was significantly lower (a maximum of approximately $30 \%$ ). The sulfide particles formed flocs with a size of several hundreds of micrometers. The quartz in turn did not form any visible flocs, and the dispersion still had a milky appearance after dosing 12,000 ppm of the flocculant. These results open a promising path for the investigation of $\mathrm{SiCNF}$ as a selective flocculation agent for sulfide minerals.
\end{abstract}

The contributing editor for this article was Zhi Sun.

Ana Luiza Coelho Braga de Carvalho

alcbdc18@tu-clausthal.de

1 Institute of Mineral and Waste Processing, Waste Disposal and Geomechanics, Department of Mineral and Waste Processing, Clausthal University of Technology, Walther-Nernst-Straße 9, 38678 Clausthal-Zellerfeld, Germany

2 Fiber and Particle Engineering Research Unit, University of Oulu, Erkki Koiso-Kanttilankatu, 90014 Oulu, Finland

3 Modelling and Mineral Processing Research Lab (LaMPPMin), Federal University of Catalão (UFCAT), 08 street 25, Catalão, GO 75705-321, Brazil 


\section{Graphical Abstract}

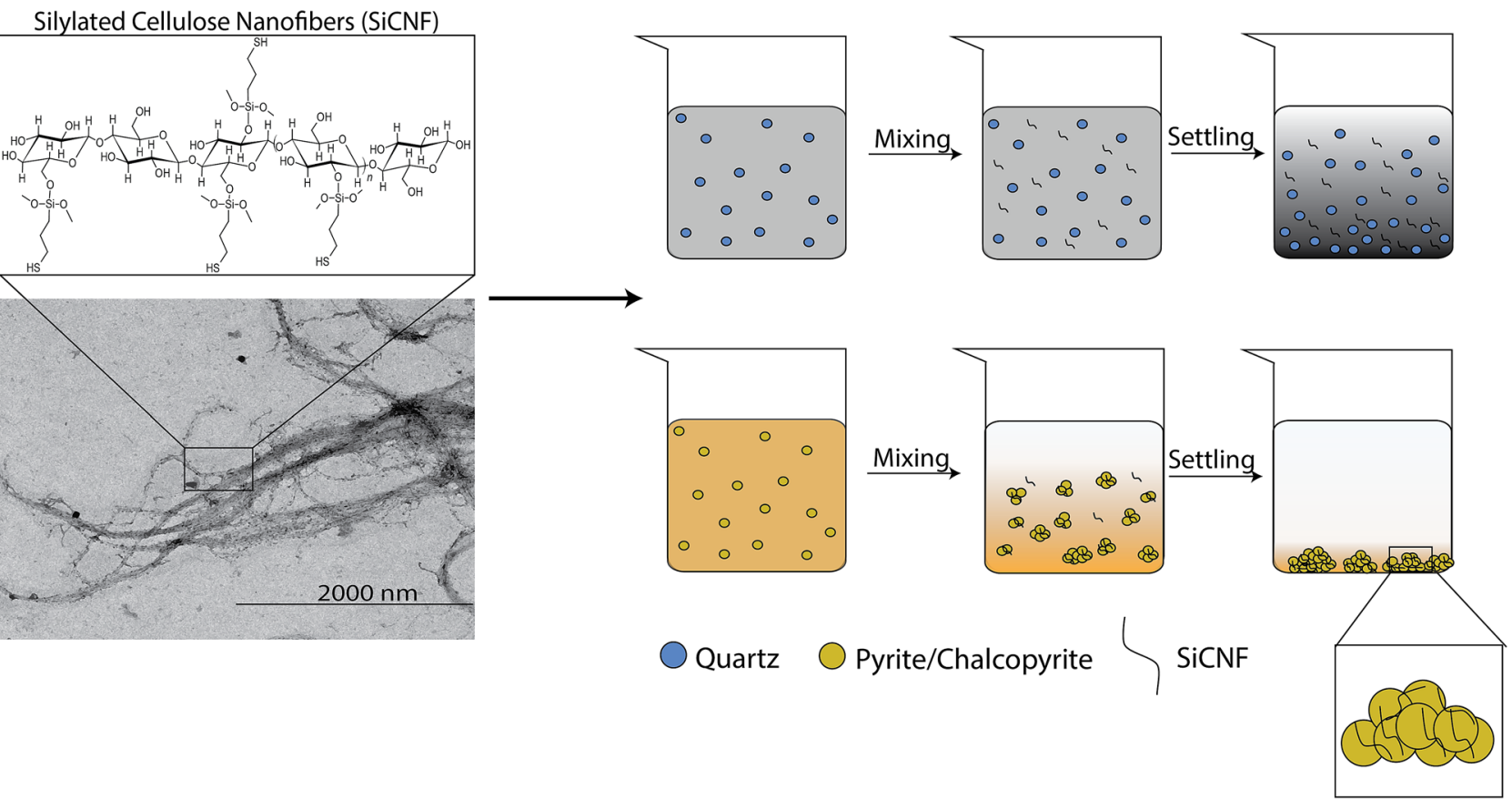

Keywords Flocculation $\cdot$ Sulfide $\cdot$ Tailings $\cdot$ Nanocellulose

\section{Introduction}

To enable mineral processing, it is usually necessary for the ore to pass through successive fragmentation stages. Along these stages, fine and ultrafine particles, technically known as slimes, are inevitably produced. The ultrafine particles in dispersions have proven to be a challenge for several reasons. For instance, in froth flotation, slimes present a decline in recovery, which is usually attributed to low collision probability and fine particles having insufficient inertia to cross the water streamlines around the coursing bubble. Problems such as surface oxidation, adsorption of metal ions, and slime coating can also be noticed $[1,2]$. As the number and grade of mineral deposits and large ore bodies have been decreasing over the years, the beneficiation of valuable minerals attributed to the fine particles has become increasingly important; moreover, there has been an increasing demand to improve conventional methods in the beneficiation of slimes $[3,4]$.

Selective flocculation, that is, the aggregation of the desired mineral particles (i.e., make them larger) and then separation (recovery) of the aggregates from the dispersed material, is one potential approach for enhancing the efficiency of fine particle processing [2]. Moreover, it appears to be an attractive method for recovering valuable minerals from slimes using, e.g., subsequent froth flotation [3, 5-9].
The principles of selective flocculation using different polymers as well as the surface chemistries have been reviewed earlier by several authors $[1-3,6,10-16]$. These techniques utilize the differences in the physical-chemical properties of the minerals and are based on the preferential adsorption of a flocculant in the mixture of colloidal solids, which results in selective flocculation and leaves the remaining particles suspended [1, 17].

The challenge in selective flocculation is mainly related to the tailored and feasible interactions between the flocculant and specific minerals. The great variety in the composition of slimes and interaction mechanisms makes it even more difficult to adjust the flocculation process [3, 18]. Moreover, hetero-coagulation, interference of dissolved ions, and entrapment of unwanted mineral particles in the flocs can also deteriorate the selectivity of flocculation. In general, the interactions and adsorption caused by the electrostatic forces and hydrogen bonding are unselective (the H-bonding is more specific than electrical forces), although the electrostatic forces can be manipulated by adjusting the surface potential of the minerals $[3,6,19-21]$. Therefore, specific chemical and coordination bonding seem to offer the most promising approach for the adsorption and flocculation of specific minerals. However, the widely used flocculants, such as polyacrylamides (PAMs), exhibit typically poor selectivity in flocculation despite their many benefits, such 
as affordability, stability, and efficiency [22]. In addition, these petroleum-derived synthetic polymers exhibit limited biodegradability [23, 24].

Nowadays, there are strong economical, ecological, and social incentives to develop novel green chemicals from renewable resources to reduce the environmental impact of mineral processing. Natural polymers, including polysaccharides, are biodegradable and are easily available from renewable side streams or forest resources [23]. Especially chitosan, starch, cellulose, alginate, and amylopectin are abundant, affordable, and nontoxic biopolymers [25]. Cellulose, for example, has been widely studied as a green alternative to existing synthetic flocculants for the development of sustainable chemicals. Nevertheless, there are certain drawbacks in cellulosic materials, such as its low solubility in water. Cellulose nanomaterials, i.e., nanocelluloses, can in turn readily be mixed with aqueous colloidal dispersions. Moreover, they have been widely studied as sustainable dispersion and emulsification agents, surfactants, and flocculants [26-30]. Cellulose nanofibers have a large surface area as well as elongated and flexible morphology; they can also be functionalized to adjust the surface characteristics $[22$, $31,32]$. Functionalized nanocelluloses have also been used earlier in the selective flocculation of mineral slimes, but the potential of functionalized nanocelluloses as flocculation agents still remains poorly understood [31].

In the flotation of sulfide minerals, selective sulfhydryl collectors, such as xanthates containing dithiocarbamates and dithiophosphates, are used [2, 33, 34]. Previously, cellulose derivatives based on these active groups, such as cellulose xanthates, have also been harnessed for the selective flocculation of lead [17], zinc [17], and copper minerals [12, 19] from a mixture containing quartz or calcite minerals $[19,35]$. However, xanthates have many drawbacks in terms of occupational health and environmental safety. They pose toxicity risks to aquatic organisms even at low concentrations [2,36-38]. Therefore, more sustainable modifications are required for the development of green alternative flocculation agents and other mineral processing chemicals from renewable sources [3, 12, 17, 19, 31, 39, 40]. In general, thiol moieties offer an appealing approach for selective interaction with the sulfide minerals. They can interact with metal ions present on the surface of the mineral to form metallic complexes [3, 19, 41].

The present study aimed to investigate silylated cellulose nanofibers (SiCNF) modified with thiol-functional moieties as an effective and sustainable flocculation agent for the dispersion of fine particles of sulfide minerals based on chalcopyrite and pyrite. The flocculation performance of $\mathrm{SiCNF}$ was tested in the dispersion of separate fine particles of chalcopyrite, pyrite, and quartz. Here, the focus was on the interactions, mechanisms, and flocculation efficiency of single mineral particle systems only; mixed systems will be the focus of our next studies. The effects of $\mathrm{pH}$ and $\mathrm{SiCNF}$ dosage on flocculation were investigated via batch experiments by measuring the residual turbidity of settled suspension and analyzing the characteristics of flocs under optical microscope. Furthermore, the aim was to compare the modified nanocellulose and its performance with a commercial anionic polyacrylamide (APAM).

\section{Materials and Methods}

\section{Raw Materials and Chemicals}

The mineral samples of pyrite, chalcopyrite, and quartz were obtained from Peru, Mexico, and Germany, respectively.

All reagents were used as received, and deionized water was utilized throughout the experiments. The commercial polymeric flocculant, Superfloc A130 (SFA130), was supplied by Kemira (Finland). It was a high-molecular-weight PAM with medium anionic charge density (33\%).

A dry sheet of industrial bleached birch (Betula verru$\cos a$ ) kraft pulp was purchased from UPM (Finland) and was used as a cellulose raw material. 3-mercaptopropyltrimethoxysilane (MPTMS, 95\%) was obtained from Sigma-Aldrich (Germany).

For $\mathrm{pH}$ adjustment, $0.1 \mathrm{M} / 1 \mathrm{M} \mathrm{NaOH}$ and $0.1 \mathrm{M} \mathrm{HCl}(\mathrm{Oy}$ FF-Chemicals Ab, Finland) were used.

\section{Preparation of Mineral Samples}

A jaw crusher (SKET, LKSB $100 \times 63$, Germany) with a $1-\mathrm{cm}$ discharge opening, followed by sieving, and a roll mill (own development) with 2-mm discharge opening were used to ground the chalcopyrite and the pyrite. Quartz had a smaller initial particle size and was ground only using a ball mill (Bond index, custom built) for $20 \mathrm{~min}$ to obtain a particle-size distribution with $\mathrm{d} 80<100 \mu \mathrm{m}$. The samples were homogenized, split, and stored. The sulfides were stored protected from contact with air to avoid oxidation.

For inductively coupled plasma-optical emission spectrometry (ICP-OES) and X-ray powder diffraction (XRD) analyses, the samples underwent a further step of comminution using a vibratory disk mill (Siebtechnik, Germany) for $3 \mathrm{~min}$. The resulting samples were stored in a desiccator before analysis.

For the flocculation tests, the minerals were further pulverized using a planetary ball mill PM 200 (Retsch, Germany) with two grinding stations of $125 \mathrm{~mL}$ at a speed of $650 \mathrm{~min}^{-1}$ for $2 \mathrm{~min}$. The sulfide samples were ground weekly and stored in small batches of $20 \mathrm{~g}$ in the fridge to avoid oxidation. Analysis of the particle-size distribution of the minerals was conducted using a Helos/BR Quixel analyzer (Sympatec, Germany). 


\section{Synthesis of Silylated Cellulose Nanofibers}

A desired amount of dry sheet of bleached birch kraft pulp was dispersed in deionized water, and the suspension was homogenized using a wet disintegrator set to $30,000 \mathrm{rpm}$ for $10 \mathrm{~min}$. A Masuko supermasscolloider grinder (MKCA6-2J, Japan) was used to disintegrate the pulp fibers to nanofibers. The stones of the grinder were first carefully brought within close contact, and then the pretreated pulp slurry was poured into the grinder at a consistency of $1.5 \%$. The gap of the grinding stones was modified from 0 to $-90 \mu \mathrm{m}$. The pulp was passed three times through the grinder using a zero-grinding stone gap; then, the stones were adjusted to negative gap values to begin the actual nanofibrillation $(-20,-40,-60$, and finally $-90 \mu \mathrm{m})$.

The silane solution $(20 \mathrm{w} / \mathrm{w} \%)$ for silylation of cellulose nanofibers was prepared by diluting MPTMS in ethanol and was then mixed with a magnetic stirrer for $10 \mathrm{~min}$. The $\mathrm{pH}$ of the CNF suspension was adjusted to 4 with $\mathrm{HCl}$ $(0.1 \mathrm{M})$, and the freshly prepared silane solution ( 0.5 times the amount of the solid content of CNF) was added dropwise using a micropipette to the pulp solution and stirred using a magnetic stirrer at room temperature for $3 \mathrm{~h}$ (Scheme 1). The cellulose suspension was then left in the oven at $85^{\circ} \mathrm{C}$ for $4 \mathrm{~h}$. Finally, the sample was washed and centrifuged with a solution of deionized water and ethanol. The degree of silylation of the fabricated silylated cellulose nanofibers (SiCNF) was determined via X-ray photoelectron spectroscopy (XPS) and sulfur analysis.

\section{Characterization}

\section{Elemental Composition of the Minerals via ICP-OES}

The elemental composition of the minerals was analyzed using ICP-OES 5100 (Agilent Technologies, USA). Melt digestion $\left(\mathrm{Li}_{2} \mathrm{~B}_{4} \mathrm{O}_{7}\right.$ melt leached with $\left.\mathrm{HCl}\right)$ was employed to analyze $\mathrm{Al}, \mathrm{K}, \mathrm{Mg}, \mathrm{Si}$, and $\mathrm{Ti}$ of minerals. To analyze $\mathrm{Ca}, \mathrm{Cu}, \mathrm{Fe}, \mathrm{Mn}, \mathrm{Pb}, \mathrm{Si}$, and $\mathrm{Zn}$, the samples were dissolved with $\mathrm{HCl} / \mathrm{HNO}_{3}$, and the residue was molten with $\mathrm{Li}_{2} \mathrm{~B}_{4} \mathrm{O}_{7}$ and leached with $\mathrm{HCl}$. To analyze sulfur, the samples were mixed with $\mathrm{MgO} / \mathrm{Na}_{2} \mathrm{CO}_{3}$, ignited $4 \mathrm{~h}$ at $815^{\circ} \mathrm{C}$, and leached with water.

\section{Characterization of the Mineral Structure via XRD}

XRD analysis was conducted via the powder method using an X'Pert Pro diffractometer (PANalytical, the Netherlands) with a position-sensitive detector and Co-k $\alpha$ radiation $(45 \mathrm{kV} / 40 \mathrm{~mA})$. The diffractograms were collected using the angular range $(2 \theta)$ of $3^{\circ}-80^{\circ}$, step size of $0.02^{\circ}$, and time per step of $25 \mathrm{~s}$. The minerals were identified by comparing the diffractograms with the International Center for Diffraction Data database.

\section{Density and Particle-Size Analysis of Minerals}

The densities of the mineral powders were determined using a gas pycnometer (Micro Pycnometer MKY-1, Quantachrome Instruments, USA); helium was utilized as the displacement gas medium. The particle-size distribution of each mineral was analyzed via laser diffractometer (Beckman Coulter LS 13 320, USA) from a 0.4\% (w/v) water slurry that had been ultrasonicated $(37 \mathrm{kHz}$, pulse mode, $100 \%$ power) for $4 \mathrm{~min}$ after grinding $10 \mathrm{~g}$ of the mineral samples (quartz, chalcopyrite, and pyrite) in a ball mill at $300 \mathrm{~min}^{-1}$ for $3 \mathrm{~min}$.

\section{Zeta Potential}

Mineral Samples The powder samples were poured into the graduated cylinder containing deionized water $(500 \mathrm{~mL})$ and $\mathrm{KNO}_{3} 10 \mathrm{mM}$ (as a background electrolyte), after which the suspensions were homogenized by agitating the capped

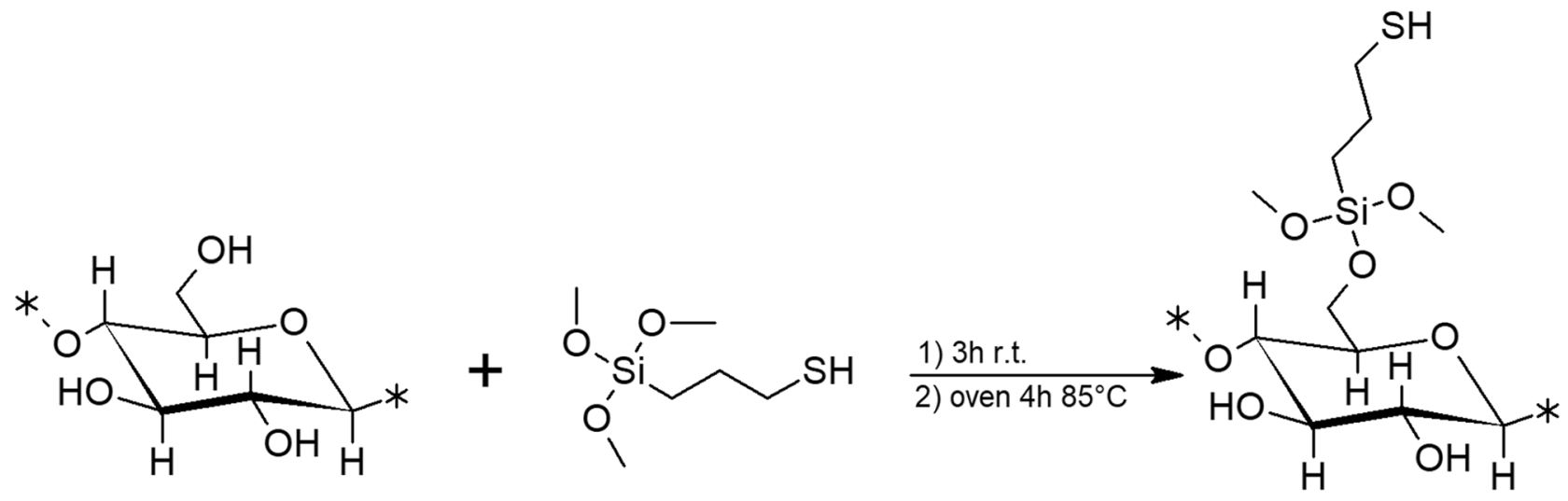

Scheme 1 Functionalization of cellulose nanofibers through an aqueous silylation reaction 
cylinder for $10 \mathrm{~min}$. The suspensions settled until solid concentrations of $0.01 \%(\mathrm{w} / \mathrm{w})$ composed of particles below $10 \mu \mathrm{m}$ were reached (calculated using Stokes' Law). Three samples $(200 \mathrm{~mL})$ of the supernatants were taken, and the $\mathrm{pH}$ was adjusted from 2 to 12 using $0.1 \mathrm{M} \mathrm{HCl}$ and $0.1 \mathrm{M}$ $\mathrm{NaOH}$. Then, the $\zeta$-potential was measured as a function of pH using the Malvern ZetaSizer Pro (Malvern Panalytical, UK). The data were collected at room temperature in auto mode, and three measurements were performed for each sample.

The mixed solutions of minerals and SiCNF were prepared according to the methodology explained above. After collecting $200 \mathrm{~mL}$ of the supernatants, SiCNF was added $(8000 \mathrm{ppm})$ and mixed for $5 \mathrm{~min}$. Then, the $\mathrm{pH}$ was adjusted to 8,9 , and 10 . Finally, the $\zeta$-potential was measured.

SiCNF Suspension The zeta potential of the aqueous suspension of SiCNF was measured at a $\mathrm{pH}$ range of 2-12 by adjusting the $\mathrm{pH}$ using $0.1 \mathrm{M} \mathrm{HCl}$ and $\mathrm{NaOH}$. The SiCNF suspension $(0.8 \% \mathrm{w} / \mathrm{w})$ was diluted to $0.1 \% \mathrm{w} / \mathrm{w}$, with a background electrolyte concentration of $10 \mathrm{mM}\left(\mathrm{KNO}_{3}\right)$ before the analysis.

\section{Transmission Electron Microscopy of SiCNF}

To visualize the structure of the $\mathrm{SiCNF}$, transmission electron microscopy (TEM) analysis was conducted using the JEM-2200FS (JEOL Ltd., Tokyo, Japan). The SiCNF suspension was placed on a sample holder using a carbon-coated copper grid. A small droplet of $0.1 \%$ polyL-lysine suspension was added to the top of the grid, and the excess was removed by touching with the corner of a filter paper. The SiCNF suspension was first diluted with deionized water, and then a small droplet was poured onto the top of the grid. Finally, a 2\% uranyl acetate solution was dropped to negatively stain the sample; the excess was removed by touching with the corner of a filter paper. The samples were dried overnight at room temperature and analyzed using an acceleration voltage of $200 \mathrm{kV}$ under standard conditions. Images were captured using the EMMenu software, whereas the ImageJ software was used to measure the length and width of the individual cellulose nanofibers.

\section{XPS Analysis of SiCNF}

The X-ray photoelectron spectra of SiCNF were measured using an X-ray photoelectron spectrometer Thermo Fisher Scientific ESCALAB 250Xi (Thermo Fisher Scientific, UK) with a monochromatic Al-K $\alpha(1486.6 \mathrm{eV})$ source.

\section{Elemental Analysis of SiCNF}

The elemental composition of the fabricated cellulose nanofibers was analyzed using a LECO CS200 analyzer (LECO Corporation, USA). Since each silylated group contains only one atom of S, the sulfur content directly corresponded to the degree of substitution (DS), which was calculated to be $0.243 \mathrm{mmol} / \mathrm{g}$.

\section{Fourier Transform Infrared Spectroscopy (FTIR) of SiCNF}

The FTIR spectra of the silylated cellulose nanofibers were recorded via Fourier transform infrared spectroscopy (Bruker Vertex v80, Indepro, Germany). The spectrum of the thin film was collected at room temperature in the transmittance mode at a resolution of $5 \mathrm{~cm}^{-1}$ in the wavenumber range of $500-4000 \mathrm{~cm}^{-1}$.

\section{Degree of Polymerization of SiCNF}

The average degree of polymerization (DP) of SiCNF was evaluated from the limiting viscosity, which was measured in cupriethylenediamine (CED) solution according to the ISO 5351 standard. The values of the limiting viscosity were converted to DP using Eq. 1, where $[\eta]$ denotes the limiting viscosity; $\mathrm{C}$, the mass fraction of cellulose; and $\mathrm{H}$, the mass fraction of hemicelluloses. This calculation makes a correction for the contribution of hemicelluloses to the limiting viscosity number and DP of cellulose [42].

$\mathrm{DP}=\frac{(1.65[\eta]-116 H)^{1.111}}{C}$

According to Eq. 1, the degree of polymerization of the silylated cellulose nanoparticles was measured to be 2569.7 .

\section{Flocculation Experiments}

Flocculation tests were conducted using $2 \mathrm{~g}$ of single minerals and $200 \mathrm{~mL}$ of deionized water $(1 \%(\mathrm{w} / \mathrm{v})$ suspension) in a $400-\mathrm{mL}$ beaker. To disperse the solids, the suspension was ultrasonicated $(37 \mathrm{kHz}$, pulse mode, $100 \%$ power, $4 \mathrm{~min}$ ) (Elmasonic P series, Germany). The experiments were conducted at varying $\mathrm{pH}$, from 8 to $10( \pm 0.3)$, using diluted $\mathrm{NaOH}$ and $\mathrm{HCl}$ solutions. After the $\mathrm{pH}$ adjustment, the beaker was placed on a stirring plate (MIXdrive 6, 2mag AG, Germany) at a speed of $800 \mathrm{~min}^{-1}$, and the flocculant was added (2000-12,000 ppm SiCNF per mass of dry mineral, representing $20-120 \mathrm{mg} / \mathrm{L}$ concentrations, and 12.5-100 ppm with SFA130 reference flocculant per mass of dry mineral, representing $0.125-1 \mathrm{mg} / \mathrm{L}$ concentrations) after $30 \mathrm{~s}$ of stirring, followed by a decrease in the stirring 
speed to $400 \mathrm{~min}^{-1}$ for $2 \mathrm{~min}$. Reference experiments without the addition of flocculants were also conducted similarly.

Then, the suspension was allowed to stand for $1 \mathrm{~min}$, after which a sample of the supernatant was removed using a 20-mL syringe from four different points, always on the same height of the beaker. The turbidity removal was calculated based on Eq. 2, by measuring the initial turbidity of the suspension and the turbidity of the supernatant after 1 min of settling time.

Turbidity $\operatorname{removal}(\%)=\frac{T_{0}-T_{\mathrm{f}}}{T_{0}} \times 100$,

where $T_{0}$ denotes the turbidity of a reference suspension before the addition of flocculant, and $T_{\mathrm{f}}$ denotes the turbidity of the supernatant of the treated sample after $1 \mathrm{~min}$. At least, two repetitions of the turbidity measurements of each sample, using a Hach Ratio/XR Turbidimeter 43,900 (Hach, USA), were performed. The standard deviation of the turbidity measurements was always below $1 \%$. The supernatants of chalcopyrite and quartz were diluted 20 and 5 times, respectively, before the turbidity measurement. Commercial APAM SFA130 was used as a reference flocculation agent.

In addition, a drop was taken from the bottom of the beaker to observe the appearance of the generated flocs using an MZ FLIII stereomicroscope (Leica Microsystems, Switzerland) equipped with a DFC320 digital camera (Leica Microsystems, Switzerland). The sample was prepared by dropping the suspensions onto a glass plate.

\section{Results and Discussion}

\section{Characteristics of Minerals}

\section{Chemical Composition}

The elemental composition of the minerals was revealed via ICP-OES analysis, and these data were used in combination with the XRD results (Fig. 1 and Table 1) to determine the mineral composition of the samples. The chalcopyrite consisted mainly of $\mathrm{CuFeS}_{2}$ (purity $\sim 76 \mathrm{wt} \% \mathrm{CuFeS}_{2}$ ) with major contaminants of $\mathrm{Fe}_{2} \mathrm{~S}(10 \mathrm{wt} \%)$ and $\mathrm{SiO}_{2}(4 \mathrm{wt} \%)$, pyrite consisted mainly of $\mathrm{Fe}_{2} \mathrm{~S}$ (purity $\sim 93 \mathrm{wt} \% \mathrm{Fe}_{2} \mathrm{~S}$ ), and quartz consisted mainly of $\mathrm{SiO}_{2}$ (purity $\sim 98 \mathrm{wt} \% \mathrm{SiO}_{2}$ ) (Table 1).

\section{XRD Analysis}

According to the XRD analysis, the primary mineral phase patterns present in the quartz and pyrite samples were attributed to quartz and pyrite, respectively, whereas in

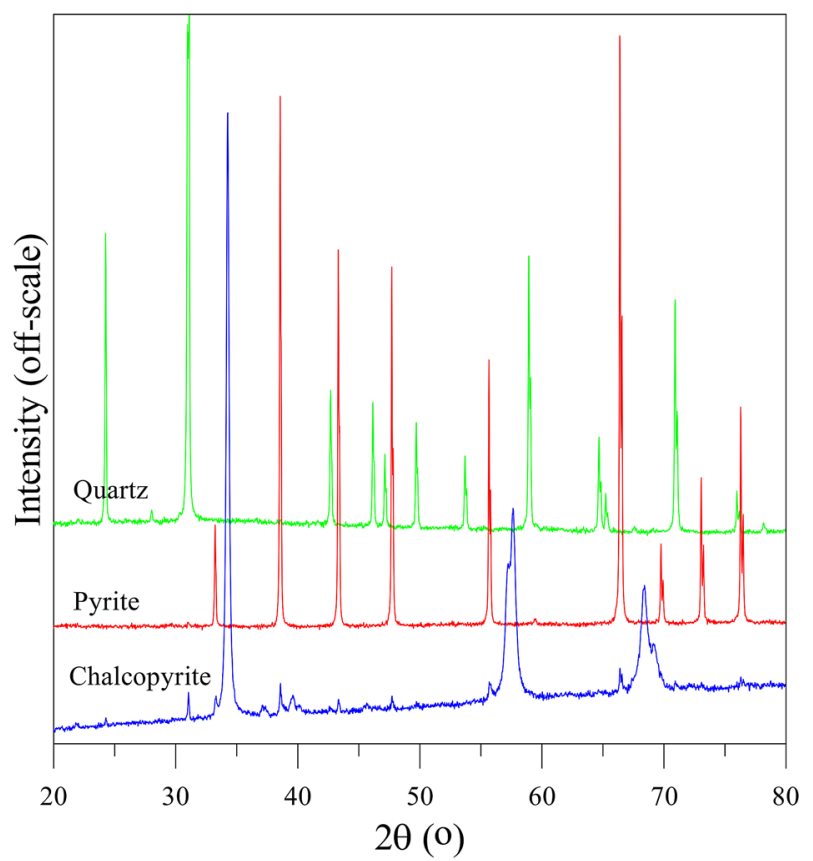

Fig. 1 XRD patterns of the quartz, pyrite, and chalcopyrite samples

Table 1 Chemical composition of the minerals

\begin{tabular}{llll}
\hline $\begin{array}{l}\text { Composition } \\
(\text { wt } \%)\end{array}$ & Chalcopyrite & Pyrite & Quartz \\
\hline $\mathrm{Al}$ & n.a & n.a & $<0.1$ \\
$\mathrm{Ca}$ & 1.39 & 0.2 & $<0.2$ \\
$\mathrm{Cu}$ & 26.5 & 0.15 & n.a \\
$\mathrm{Fe}$ & 27.7 & 43.3 & 0.24 \\
$\mathrm{~K}$ & n.a & n.a & $<0.2$ \\
$\mathrm{Mg}$ & n.a & n.a & $<0.04$ \\
$\mathrm{Mn}$ & n.a & n.a & 0.00 \\
$\mathrm{~Pb}$ & 0.14 & 0.04 & n.a \\
$\mathrm{S}$ & 31.1 & 50.1 & n.a \\
$\mathrm{Si}$ & 1.98 & 0.14 & 45.66 \\
$\mathrm{Ti}$ & n.a & n.a & $<0.01$ \\
$\mathrm{Zn}$ & 0.77 & 0.09 & 0.04 \\
\hline
\end{tabular}

n.a. not analyzed

the chalcopyrite sample, the main pattern of chalcopyrite appeared with small quantities of quartz and pyrite residues (Fig. 1).

\section{Particle-Size Distribution}

Table 2 and Fig. 2 present the particle-size distributions of the minerals. The volumetric median diameters of chalcopyrite, pyrite, and quartz were $9.3 \mu \mathrm{m}( \pm 0.3 \mu \mathrm{m}), 4.3 \mu \mathrm{m}$ $( \pm 0.4 \mu \mathrm{m})$, and $8.1 \mu \mathrm{m}( \pm 0.4 \mu \mathrm{m})$, respectively. All minerals 
Table 2 Cumulative particle size of chalcopyrite, pyrite, and quartz obtained using a laser diffractometer

\begin{tabular}{llllllc}
\hline Mineral & $d_{10}(\mu \mathrm{m})$ & $d_{20}(\mu \mathrm{m})$ & $d_{50}(\mu \mathrm{m})$ & $d_{75}(\mu \mathrm{m})$ & $d_{90}(\mu \mathrm{m})$ & $d_{100}(\mu \mathrm{m})$ \\
\hline Chalcopyrite & 0.5 & 0.9 & 3.4 & 9.8 & 23.8 & 103.0 \\
Pyrite & 0.2 & 0.4 & 2.0 & 6.1 & 11.6 & 37.7 \\
Quartz & 0.9 & 1.4 & 4.6 & 11.8 & 20.8 & 47.0 \\
\hline
\end{tabular}

Fig. 2 Particle-size distributions of chalcopyrite, pyrite, and quartz

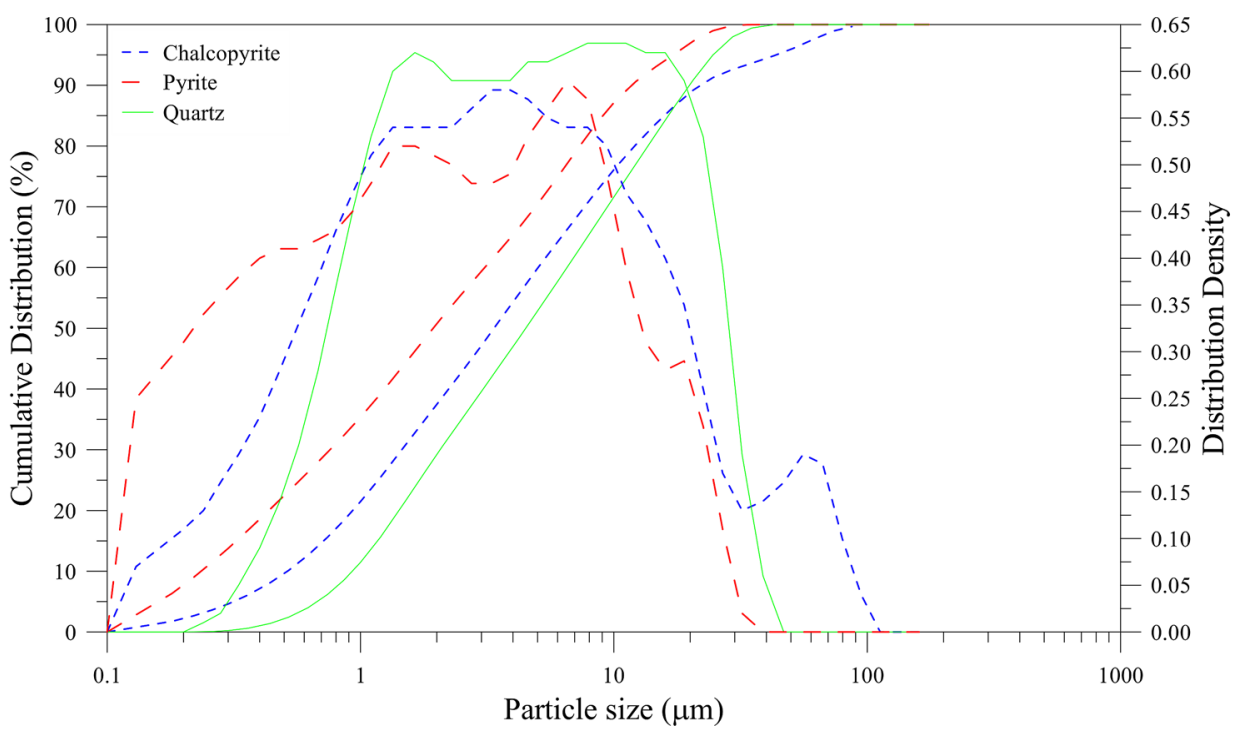

presented similar particle-size distribution, but pyrite contained a slightly larger proportion of small particles, whereas chalcopyrite had still a larger particle fraction left.

\section{Zeta Potential}

The zeta potential values of chalcopyrite, pyrite, and quartz were measured in aqueous solutions as a function of $\mathrm{pH}$, and the results are presented in Fig. 3. All the minerals exhibited a negative charge density above the $\mathrm{pH}$ of approximately 4 (except pyrite, which demonstrated only negative values), which decreased almost linearly with all minerals as a function of $\mathrm{pH}$, from -30 to $-40 \mathrm{mV}$ at a $\mathrm{pH}$ of 12 . The isoelectric point (IEP) of chalcopyrite and quartz occurred around $\mathrm{pH} 3.0-3.5$ and around $\mathrm{pH} 3.5-4.0$ respectively. However, the IEP of pyrite was not observed within the studied $\mathrm{pH}$ range (2-12), as the zeta potential demonstrated only negative values.

Variable values for the IEP of chalcopyrite, pyrite, and quartz have been previously reported. Dhar et al., Rath et al., and Reyes-Bozo et al. [43-45] determined the IEP of chalcopyrite to be around $\mathrm{pH} 3.0-4.2$, which agrees with the results of the present work. However, Mitchell et al. [46] found the IEP at pH 5.5 for a sample containing 65\% chalcopyrite. According to Dhar et al. and Somasundaram [45, 47], the IEP of quartz was observed at $\mathrm{pH} 2.1$, which is a lower value than that observed in the current study. However, Liang et al.

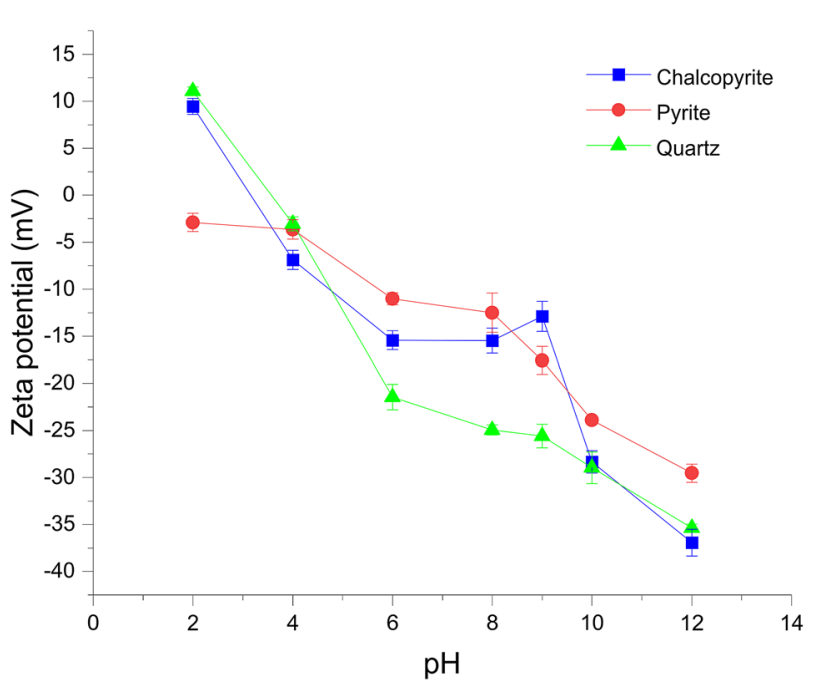
function of $\mathrm{pH}$ at a constant ionic strength of $10 \mathrm{mM} \mathrm{KNO}_{3}$. Lines do not necessarily represent linear trends

[48] have reported that the zeta potential of quartz remained negative and decreased from -23 to $-49 \mathrm{mV}$ as $\mathrm{pH}$ increased from 4 to 10, demonstrating a similar trend to that of the present work. Moreover, Yukselen-Aksoy and Kaya [49] found that the zeta potential changed from $-30.2 \mathrm{mV}$ at $\mathrm{pH}$ 3 to $-65.4 \mathrm{mV}$ at $\mathrm{pH} 11$, whereas $\mathrm{Wu}$ et al. and $\mathrm{Xu}$ et al.
Fig. 3 The zeta potential $(\mathrm{mV})$ of chalcopyrite, pyrite, and quartz as a 
$[50,51]$ corroborated that the zeta potential remained negative from $\mathrm{pH} 3$ to 10 with the IEP at a $\mathrm{pH}<2.5$. Mitchell et al., Patra and Natarajan, and Reyes-Bozo et al. [46, 52, 53] reported that the IEP of pyrite occurs between $\mathrm{pH} 2$ and 2.5. In addition, Liu and Huang [54] have reported that pyrite has an IEP at $\mathrm{pH}$ lower than 3.0. However, Reyes-Bozo et al. [44] observed that the IEP of pyrite occurs at $\mathrm{pH}$ 8.1. Here, the results suggest that the IEP of pyrite occurred at a very low $\mathrm{pH}(<2)$.

Overall, different factors affect the electrokinetic behavior of sulfide minerals, such as the purity of the mineral, surface oxidation, sample pretreatment, source of the mineral, and background electrolytes $[44,54]$. Therefore, the zeta potential values of the same minerals can significantly vary.

\section{Properties of Silylated Cellulose Nanofibers}

\section{Morphology}

Functionalized cellulose nanofibers with thiol moieties were synthesized using an aqueous silylation reaction based on MPTMS. The silylated nanofibers, which were individualized using ultrafine grinding, exhibited a typical elongated and flexible nanofibrillar morphology, as revealed by the TEM images (Fig. 4) [32]. The width of the smallest, individual SiCNFs varied from 2 to $5 \mathrm{~nm}$ (as analyzed of $>300$ individual nanofibers using the ImageJ software), whereas the length ranged from $100 \mathrm{~nm}$ to several micromevters according to visual observations. However, the length of the individual particles was difficult to determine, as the nanofibers formed an entangled network structure. SiCNF consisted of separate cellulose nanofibers but also contained a notable portion of larger bundles of nanofibers with a diameter of several tens of nanometers.

\section{Elemental Analysis}

The amount of silylated groups in SiCNF was determined using an elemental analyzer. Since each silylated group contains only one atom of S (Scheme 1), the sulfur content corresponded directly to the amount of silylated groups, which was calculated to be $0.243 \mathrm{mmol} / \mathrm{g}$. This result indicated that the CNF was successfully functionalized with MPTMS. The sulfur and carbon contents were also investigated via XPS analyses, indicating that $\mathrm{SiCNF}$ has a $\mathrm{C}$ content of 55.65 wt. \% (46.33 mmol/g) and $\mathrm{S}$ content of 0.53 wt. \% $(0.165 \mathrm{mmol} / \mathrm{g})$. The $\mathrm{S}$ content observed via the XPS analysis was lower compared with the value obtained via the elemental analysis, likely because the XPS analyzer gives chemical information about the 10-nm surface layer of the sample, whereas the whole sample is analyzed via the elemental analysis.

\section{Chemical Structure}

FTIR was further employed to analyze the chemical structure of SiCNF and to prove the successful reaction between the CNF and MPTMS (Fig. 5). Silylation was confirmed by the existence of several characteristic peaks associated with the silylated product. Vibration peaks at $837-900 \mathrm{~cm}^{-1}$ are assigned to glycosidic bonds (related to $\mathrm{C}_{1}-\mathrm{H}$ deformation vibrations), peaks at $1042-1135 \mathrm{~cm}^{-1}$ are related to $\mathrm{Si}-\mathrm{O}-\mathrm{Si}$ and $\mathrm{Si}-\mathrm{O}-$ cellulose bonds, whereas peak at $1181 \mathrm{~cm}^{-1}$ corresponds to $\mathrm{Si}-\mathrm{CH}$ bond. The band at $1462 \mathrm{~cm}^{-1}$ is related to the bending vibrations of $\mathrm{H}-\mathrm{C}-\mathrm{H}$ and $\mathrm{O}-\mathrm{C}-\mathrm{H}$, and the

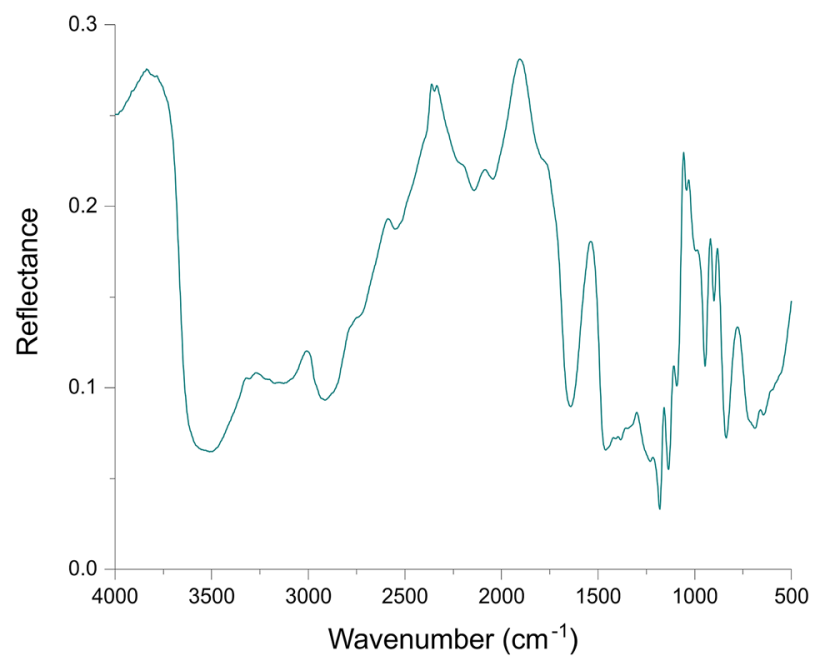

Fig. 5 FTIR spectrum of silylated cellulose nanofiber
Fig. 4 TEM images of silylated cellulose nanofibers

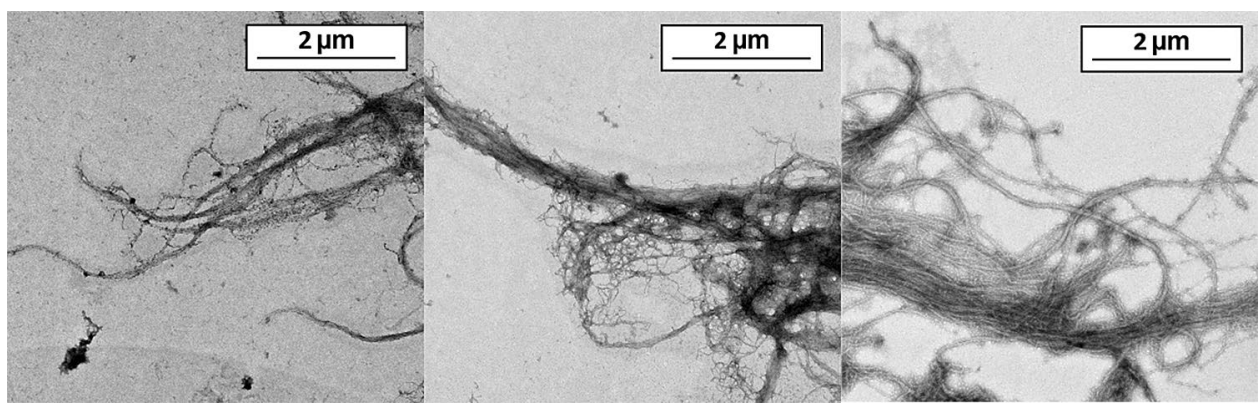


peak at $1642 \mathrm{~cm}^{-1}$ is the bending vibration of the $\mathrm{OH}$ groups of the adsorbed water. The typical peak of the thiol group $(\mathrm{S}-\mathrm{H})$ was observed at $2550 \mathrm{~cm}^{-1}$, whereas the band at $2914 \mathrm{~cm}^{-1}$ is assigned to $\mathrm{C}-\mathrm{H}$ (bond with $\mathrm{SH}$ ). The peaks at $3129-3512 \mathrm{~cm}^{-1}$ represented O-H stretching of the cellulose [42, 55-61].

\section{Zeta Potential}

The zeta potential of SiCNF was measured as a function of $\mathrm{pH}(2-12)$ in the aqueous solution with a background electrolyte concentration of $10 \mathrm{mM}\left(\mathrm{KNO}_{3}\right)$; the results are presented in Fig. 6. The SiCNF exhibited a negative zeta potential, which decreased almost linearly as a function of $\mathrm{pH}$, being between -3 and $-27 \mathrm{mV}$. The IEP of the modified cellulose was not observed within the studied $\mathrm{pH}$ range.

\section{Flocculation of Mineral Suspensions Using SiCNF}

\section{Turbidity Removal}

The flocculation performance of SiCNF in the dispersion of the fine particles of chalcopyrite, pyrite, and quartz ( $1 \%$ $\mathrm{w} / \mathrm{v}$ ) was analyzed in terms of turbidity removal via batch experiments (Figs. 7, 8, 9). A commercial APAM, Superfloc A130 (SFA130), was used as a reference flocculation agent. The efficiency of the turbidity removal was observed to be always better for chalcopyrite and pyrite suspensions compared with quartz suspensions both with SiCNF and the reference flocculation agent, indicating a more efficient and effective flocculation of sulfide minerals.

High efficiency of turbidity removal (maximum of approximately $90 \%-99 \%$ ) was noted with chalcopyrite at

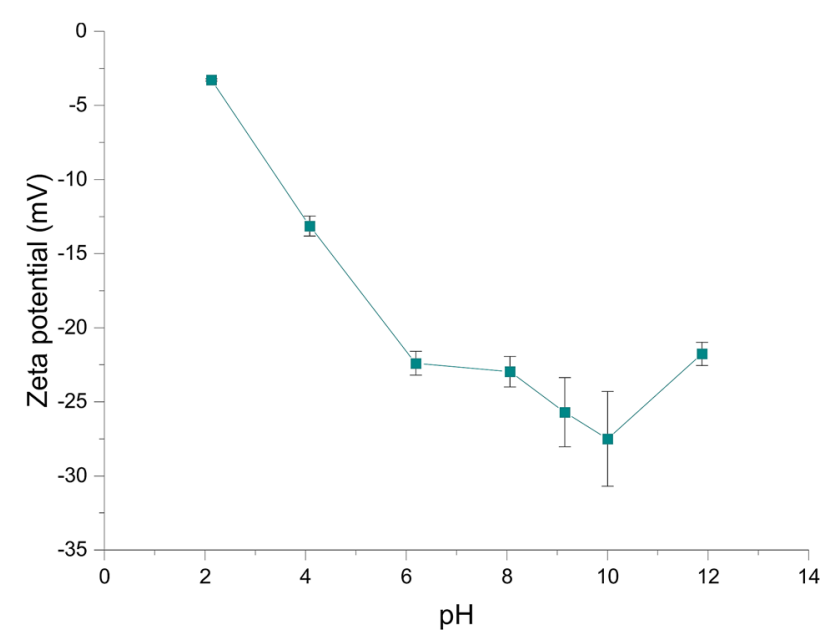

Fig. 6 The zeta potential (mV) of SiCNF (silylated cellulose nanofibers) as a function of $\mathrm{pH}$ at a constant ionic strength of $10 \mathrm{mM} \mathrm{KNO}_{3}$. Lines do not necessarily represent linear trends all studied $\mathrm{pH}$ values $(8,9$, and 10$)$ both with SiCNF and the commercial flocculation agent (Fig. 9a and b). A similar trend was also observed with pyrite (the maximum turbidity removal for SiCNF and SFA130 was approximately $90 \%$ and $99 \%$, respectively), but the flocculation performance of SiCNF was more affected by $\mathrm{pH}$ (Fig. 10a and b). At $\mathrm{pH}$ 9 and 10, the maximum flocculation efficiency dropped to approximately $75 \%$ and $65 \%$, respectively, with SiCNF.

The turbidity removal of quartz suspension was notably lower than that of sulfide minerals with both flocculants (Fig. 11a and b). The flocculation performance was also strongly attributed to the $\mathrm{pH}$ of the suspension, and the maximum turbidity removal of approximately $30 \%$ was reached at $\mathrm{pH} 8$. The clear difference between the flocculation behavior of sulfide minerals and quartz was also observed in the visual appearance of mineral suspensions (Figs. 9c, 10c, 11c). The chalcopyrite and pyrite dispersions exhibited a gradual increase in transparency as a function of SiCNF concentration, whereas the quartz dispersion maintained its milky and turbid appearance despite the increase in SiCNF dosage.

The most significant difference between SiCNF and the commercial flocculation agent was shown in the required optimal flocculant dosage. The maximum turbidity removal of SFA130 was obtained at a concentration of $50 \mathrm{ppm}$ with all minerals. The required concentrations for SiCNF were in turn much higher, i.e., 4000-8000 ppm. The reason behind the higher concentrations of SiCNF is partly related to the fact that SiCNF was based on fibrous nanoparticles with larger spatial dimensions and lower specific surface area than that of soluble polymeric flocculant. The hydrodynamic diameter of polymer molecules with a molecular weight of $2 \cdot 10^{6}$ was reported to be approximately $85 \mathrm{~nm}$ [22], whereas SiCNF had a length ranging from $100 \mathrm{~nm}$ to several micrometers. Previously, efficient agglomeration of hematite was reported with dosages of 200-500 ppm using anionic dicarboxylic acid (DCC) and sulfonated (ADAC) cellulose nanofibers [31].

The low DS of SiCNF may have also influenced the required flocculant dosages [62]. Cationic cellulose nanocrystals (CNC-EPTMAC) synthesized through a reaction of the 3-chloro-2-hydroxypropyltrimethylammonium chloride (CHPTAC) in basic medium was found to have a better performance in the flocculation of the $\mathrm{SiO}_{2}$ suspension when the DS, i.e., the cationic charge density of CNCs, increased. Grenda et al. [63] in turn observed that the influence of flocculant dosage was more pronounced for cellulose-based flocculants with a lower DS. In addition, the high charge density and DS of cationic cellulose-based polyelectrolytes led to a superior flocculation performance in terms of floc growth, especially at lower flocculant dosages.

Different from the present study, previously anionic cellulosic flocculants, with diverse lignin contents, 
Fig. 7 Turbidity removal of chalcopyrite suspension using a $\mathrm{SiCNF}$ and b SFA130 as a flocculation agent $(\mathrm{pH}=8-10)$ and c the visual appearance of the supernatant of the chalcopyrite suspension after using $\mathrm{SiCNF}$ as a flocculant at $\mathrm{pH} 10$ (from left to right, concentrations equal to $0,2000,4000,8000$, and 12,000 ppm)
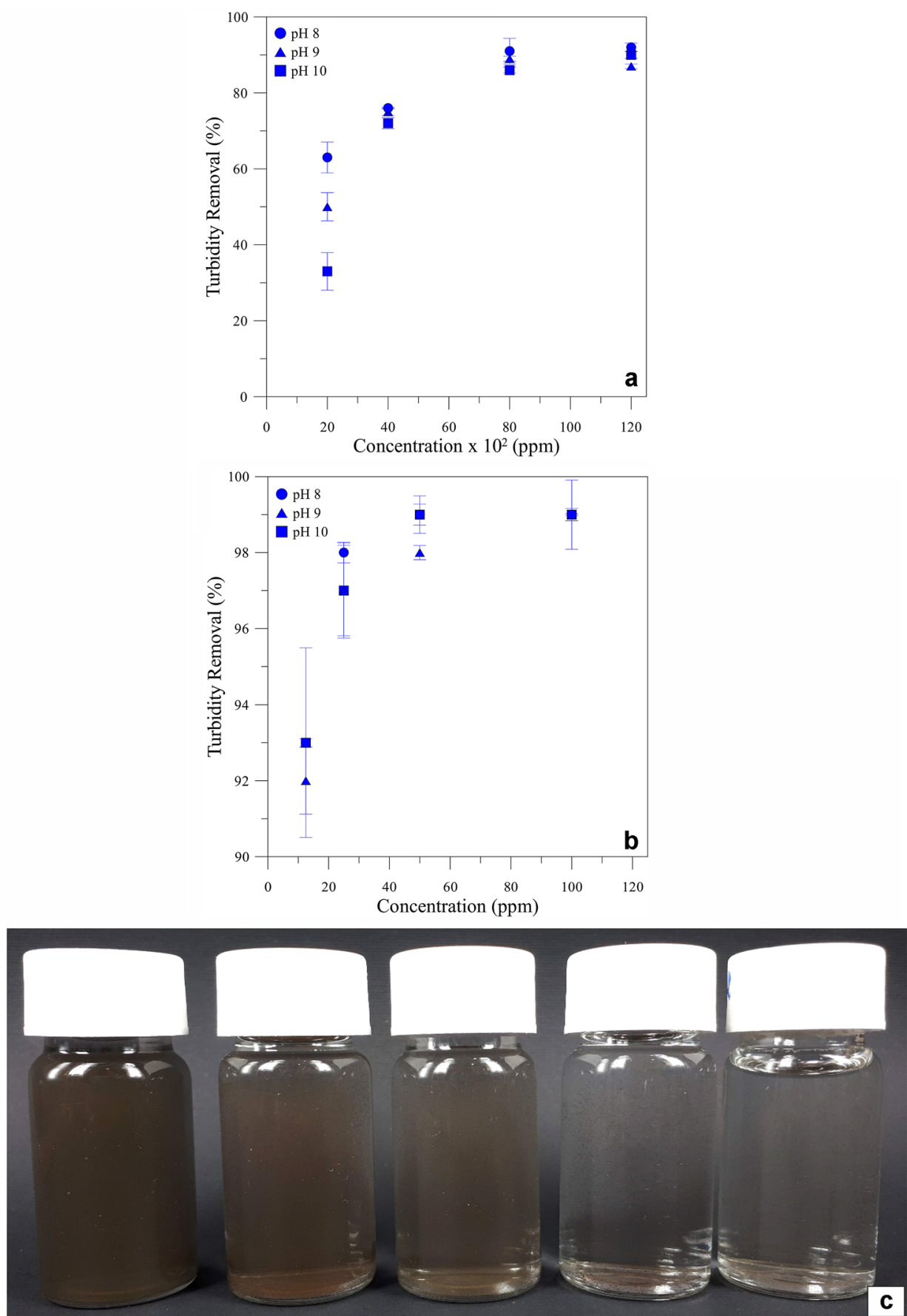

resulted in a lower turbidity reduction in effluent treatment when compared with the performance of the synthetic APAM with the same $\mathrm{pH}$ levels [63]. This weaker flocculation performance of cellulose-based flocculant was attributed to a slightly lower charge density and molecular weight than that of APAM.

\section{Properties of Mineral Flocs Formed by SiCNF}

Figure 10 presents the optical microscopy images of flocs of pyrite and chalcopyrite formed using $2000 \mathrm{ppm}$ of SiCNF at $\mathrm{pH}$ 8. In both cases, mineral particles formed typical irregular fluffy flocs with the largest mean 
Fig. 8 Turbidity removal of the pyrite suspension using (a) SiCNF and (b) SFA130 as a flocculation agent $(\mathrm{pH}=8-10)$ and (c) the visual appearance of the supernatant of the pyrite suspension after using $\mathrm{SiCNF}$ as a flocculant at $\mathrm{pH} 10$ (from left to right, concentrations equal to $0,2000,4000,8000$, and 12,000 ppm)
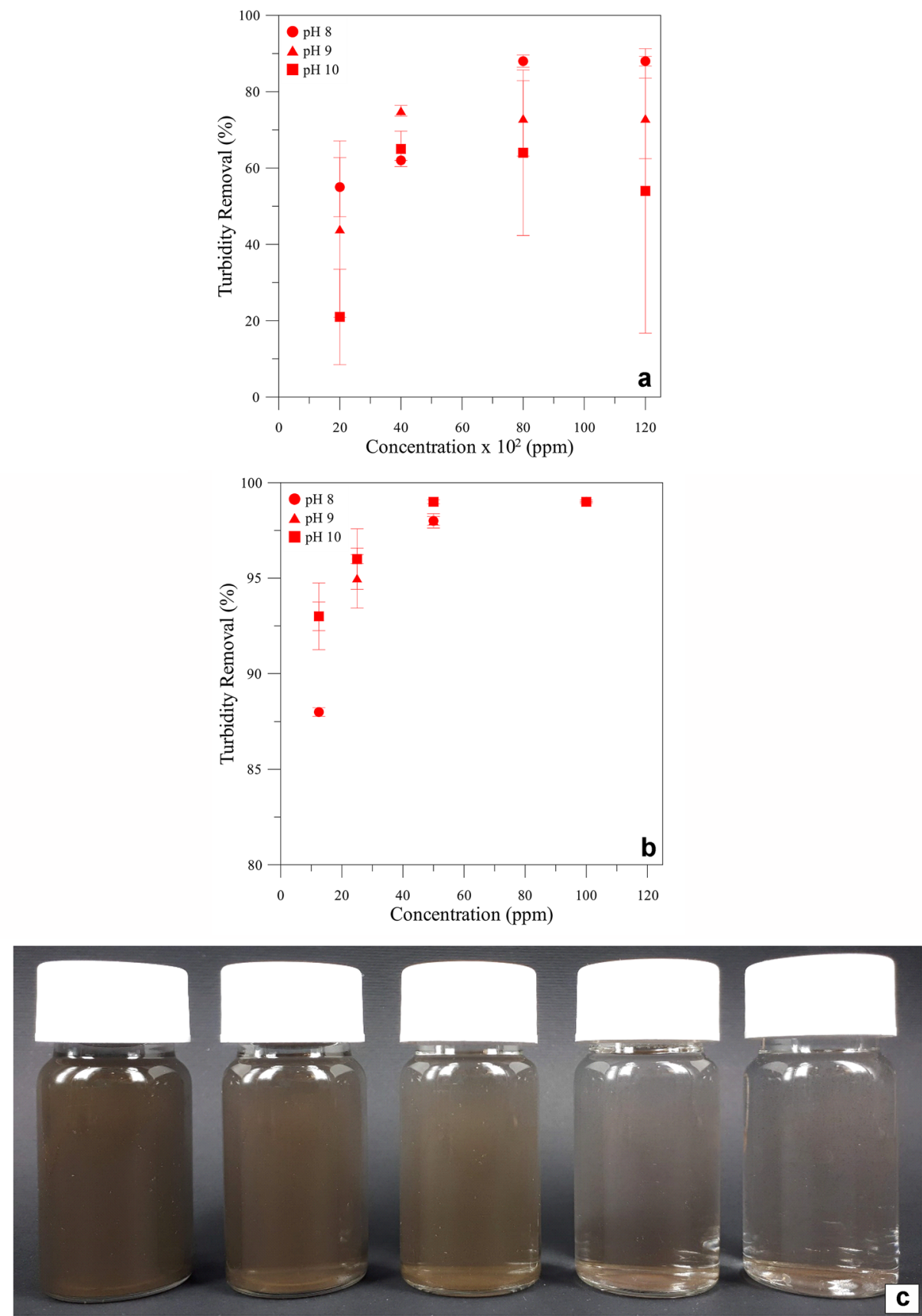

particle size of several hundreds of micrometers; however, some smaller, more round-shaped aggregates were also observed. The flocs resembled the flocs previously reported for ultrafine hematite particles and anionic cellulose nanofibers [31] and those observed in the flocculation of pyrite fine particles using corn starch [24]. The flocs of pyrite were found to be denser and were likely able to resist better shear forces without breakage compared with those of chalcopyrite. The quartz in turn did not form any visible flocs (Fig. 11c), and the dispersion still exhibited a turbid appearance after dosing the flocculant, which supported the finding that SiCNF had a better efficiency toward sulfide minerals.

Considering the evolution of the floc size with time, it was observed that in the first seconds of the flocculation process predominated and resulted in large aggregates. After achieving the maximum floc size, the large flocs started to break; subsequently, the equilibrium between breakage and re-aggregation was achieved, and the floc size stabilized. A similar behavior was observed in the previous works in the flocculation of colored effluent using PAM and anionic and cationic cellulose-based polyelectrolytes [63] as well as 
Fig. 9 Turbidity removal of the quartz suspension using a $\mathrm{SiCNF}$ and b SFA130 as a flocculation agent $(\mathrm{pH}=8-10)$ and $\mathbf{c}$ the visual appearance of the supernatant of quartz suspension after using $\mathrm{SiCNF}$ as a flocculant at $\mathrm{pH} 10$ (from left to right, concentrations equal to $0,2000,4000,8000$, and 12,000 ppm)
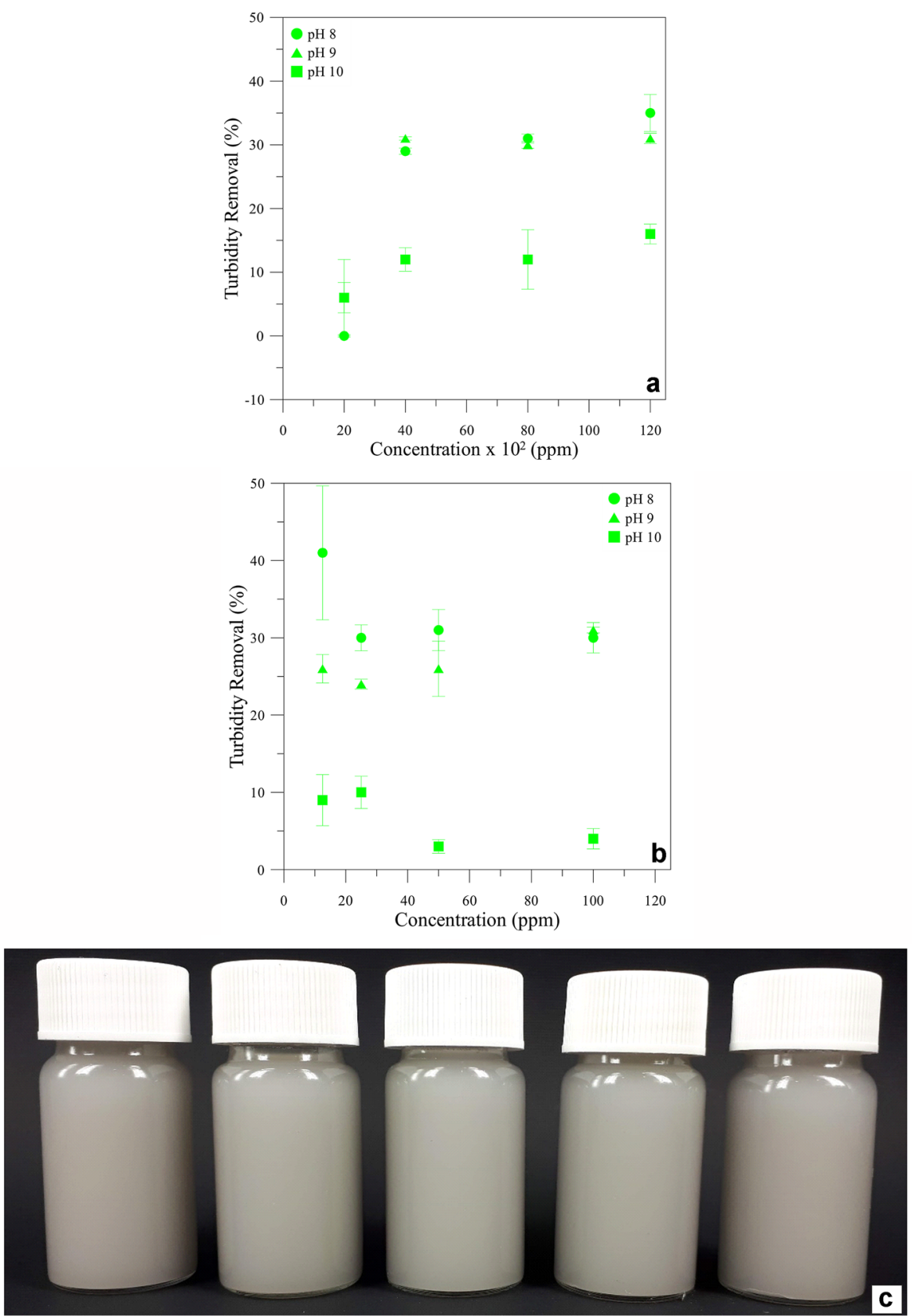

in the flocculation of pyrite fine particles using corn starch [24].

\section{Zeta Potential of Mixed Dispersions of Single Minerals and SiCNF}

The zeta potential of mixed dispersions of single mineral particles and SiCNF was measured as a function of $\mathrm{pH}$ (2-12) using a flocculant dosage of 8000 ppm (Fig. 11). The measurements were performed under a constant ionic strength $\left(10 \mathrm{mM} \mathrm{KNO}_{3}\right)$. Both the minerals and SiCNF initially exhibited a negative charge density at $\mathrm{pH} 8,9$, and 10; the same $\mathrm{pH}$ range used in the flocculation tests.

All the mixed dispersions demonstrated a negative zeta potential value, which decreased as a function of $\mathrm{pH}$, similar to the original zeta potential values of both separate mineral and SiCNF samples (Figs. 3 and 6). The zeta potential values of a mixture of quartz and SiCNF were close to that of the original quartz suspension. This behavior indicated that the suspension charge properties were dominated by the mineral particles (concentration of quartz $>>$ concentration of $\mathrm{SiCNF}$ ) instead of SiCNF, which likely did not adsorb on mineral surfaces and stayed in the suspensions as separate 


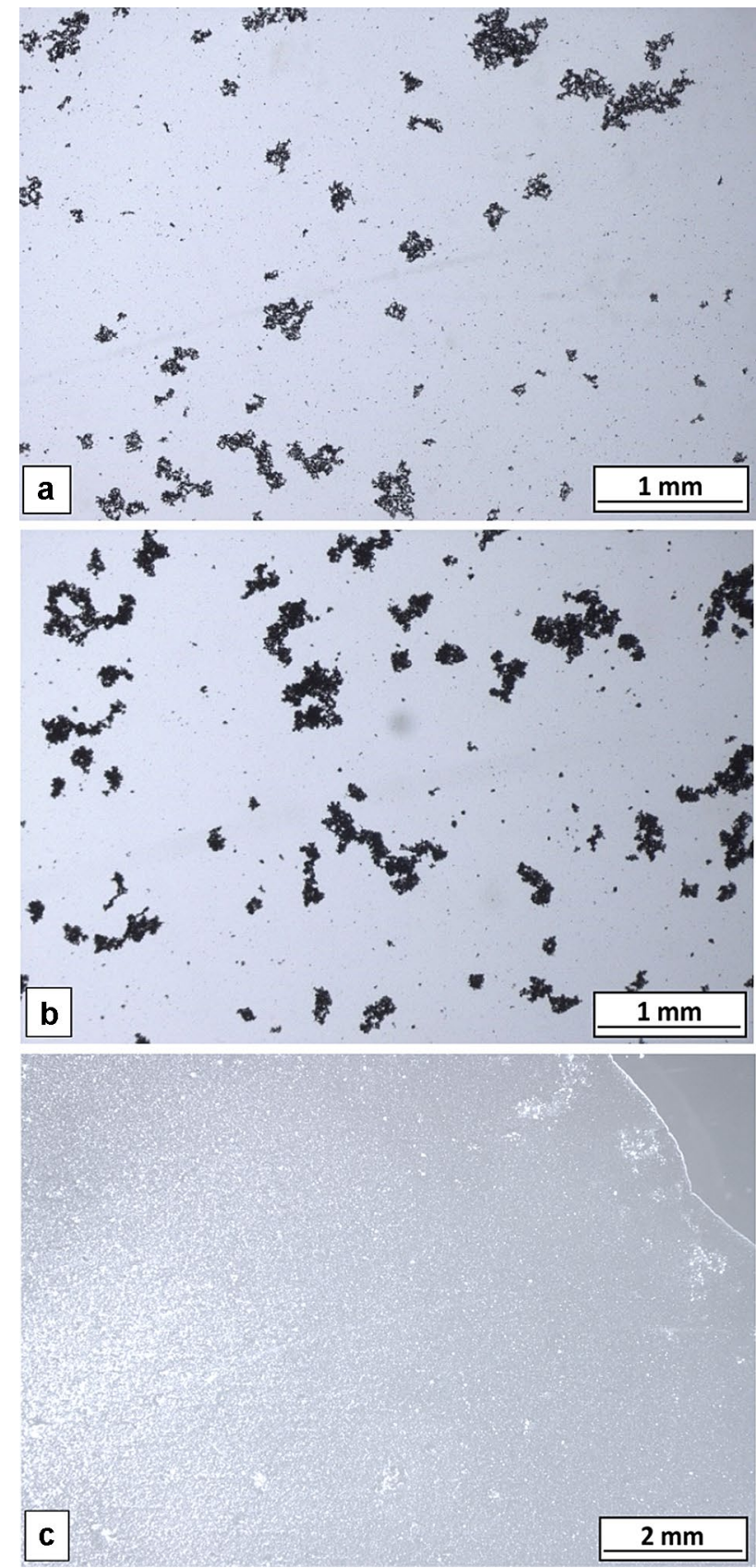

Fig. 10 Microscopic image of $\mathbf{a}$ chalcopyrite, $\mathbf{b}$ pyrite, and $\mathbf{c}$ quartz after flocculation using SiCNF (2000 ppm of SiCNF at pH 8)

entities. Moreover, the flocculation results supported this finding. For the mixtures of chalcopyrite and SiCNF as well as pyrite and SiCNF, the level of zeta potential was in turn different from that of pure minerals at $\mathrm{pH} 8,9,10$ (except at $\mathrm{pH} 9$ with chalcopyrite and $\mathrm{SiCNF}$ ). This alteration in the zeta potential was presumably caused by the interaction between $\mathrm{SiCNF}$ and the sulfide minerals, which resulted in the adsorption of SiCNF on the surface of chalcopyrite and pyrite particles. Previous work by Sresty and Somasundaran
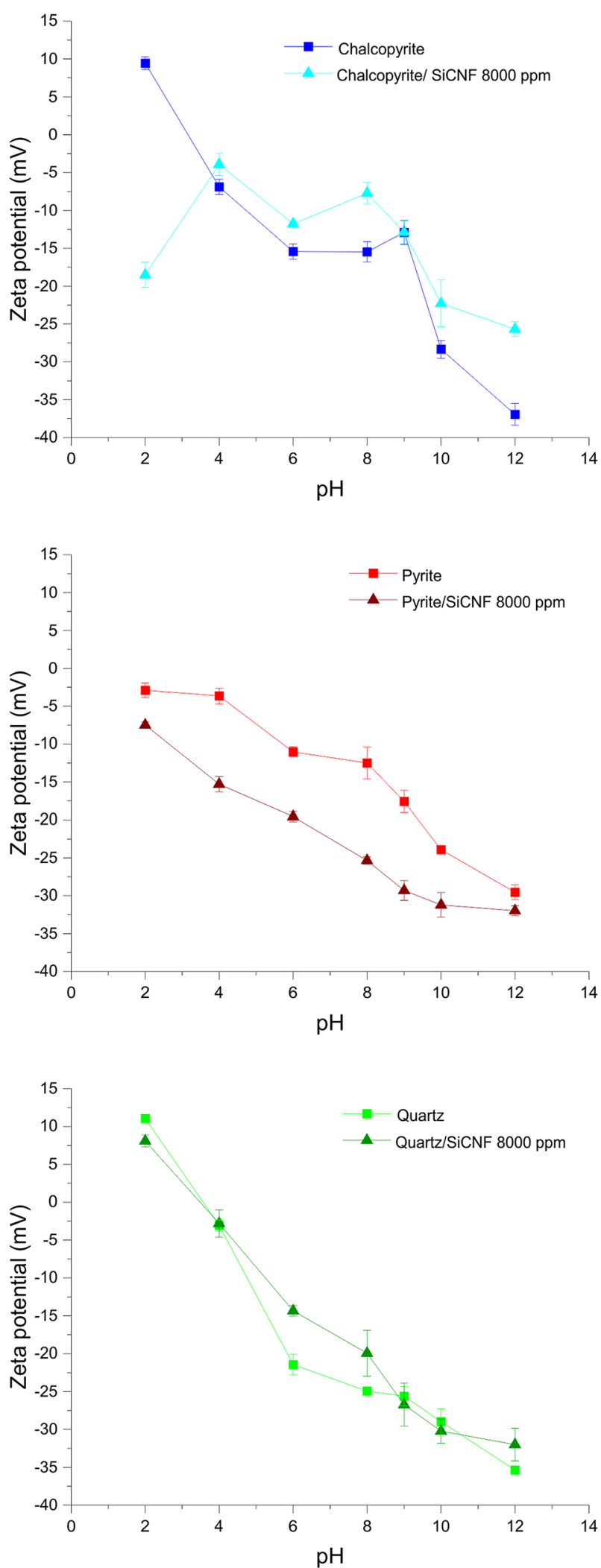

Fig. 11 The zeta potential (mV) of a chalcopyrite and $8000 \mathrm{ppm}$ of $\mathrm{SiCNF}$, b pyrite and $8000 \mathrm{ppm}$ of SiCNF, and $\mathbf{c}$ quartz and $8000 \mathrm{ppm}$ of $\mathrm{SiCNF}$ as a function of $\mathrm{pH}$ at a constant ionic strength of $10 \mathrm{mM}$ $\mathrm{KNO}_{3}$. Lines do not necessarily represent linear trends 
[19] investigated the zeta potential of fine hematite particles as a function of concentration of polystyrene sulfonate flocculant at $\mathrm{pH} 7.8$, in which both the mineral and polymer were negatively charged. It was pointed out that the adsorption of the polymer molecules on the mineral surface led to a significant shift in the shear plane of mineral particles and that the change in the zeta potential was considered to be a good measure of the adsorbed polymer layer rather than that of the original particles themselves [19].

\section{Interaction and Flocculation Mechanism of SiCNF}

In the studied $\mathrm{pH} 8,9,10$, both the flocculants and minerals demonstrated a negative surface charge (Figs. 3 and 6). Similar surface charges can result in electrostatic charge repulsion and prevent efficient interaction between the flocculant and minerals as well as further formation of flocs. However, this is often not the case in practice [22]; the adsorption of anionic polymers on negative surfaces is a common phenomenon and is promoted by specific chemical interactions $[3,23]$, contrary to physical adsorption, which is driven by the opposite surface charges of a reagent and surface [64].

Previously, mine tailings consisting of negatively charged clay particles were flocculated with high-molecular-weight APAMs in alkaline medium [22]. The electrostatic repulsion between polymer chains and the negatively charged surfaces of the clays caused the polymer to adsorb primarily on the neutral edges of the clay particles, thus, increasing the possibility that the same PAM chain can extend into the solution and adsorb on the surface of other particles and form large and porous aggregates. An anionic cellulose-based flocculant was in turn found to interact with negatively charged bentonite-dye complex through the sulfonate groups (electrostatic) or hydroxyl groups (hydrogen bonding) of the cellulose structure [63].

Here, the interactions between SiCNF and sulfide minerals were likely attributed to the thiol $(-\mathrm{SH})$, and the hydroxyl functional moieties of the cellulose polymer surface, bonding with the hydroxyl species and metal compounds that formed on the mineral surface. A similar mechanism of interaction was observed in the flocculation of sulfide minerals with insoluble cross-linked starch xanthate [40], in which a covalent bond formation between the xanthate group and metal components on the mineral surface of chalcopyrite was observed.

The specific interaction between SiCNF and pyrite or chalcopyrite caused flocculation of sulfide minerals, which was presumably mediated by a bridging mechanism. This mechanism was supported by the fast flocculation rate and relatively open aggregates (Fig. 10). However, it is likely that the electrostatic repulsion between the mineral particles and polymers could allow only a limited polymer adsorption. However, the polymer molecule expansion arising from the charge repulsion induces the production of loops and tails, which lead to the formation of large open-structure flocs. This effect has been found to be effective in the flocculation of negatively charged clay dispersions as cited in the study by Nasser and James [65]. The bridging mechanism is also favored by long-chain length and elongated structure of the flocculant $[66,67]$. Here, both SiCNF and SFA130 consisted of long and flexible ribbons.

Both SiCNF and SFA130 demonstrated poor flocculation performance with quartz. Apparently, SiCNF did not show a strong specific affinity for quartz surfaces in an aqueous solution; moreover, there was no (or very low) adsorption of SiCNF on the quartz particles as supported by the zeta potential measurement (Fig. 11). Similar results were obtained in previous works on the flocculation of fine hematite particle and quartz suspensions with anionic cellulose nanofibers [31] and in a selective flocculation of complex sulfides using cellulose xanthate [17]. This effect was explained by the high repulsive forces between the anionic flocculants with quartz. Moreover, the strong electrostatic repulsion between the negatively charged quartz particles and the APAM appeared to prevent the adsorption of APAM on the quartz surface as cited in the study by Somasundaran [9]. Therefore, the effect of the surface charge of the minerals is of high importance in flocculation, as it can potentially prevent efficient flocculation by providing a strong electrostatic repulsion [3, 6, 19]. Calcite-rutile, calcite-quartz, and alumina-quartz mixtures were readily separable on this basis via selective flocculation [6].

In the current study based on single mineral systems, SiCNF strongly reduced the turbidity of the pyrite and chalcopyrite suspensions by promoting the aggregation of fine minerals to larger flocs while exerting a minor effect on the flocculation of quartz suspensions under the studied conditions. Consequently, these results indicate that $\mathrm{SiCNF}$ could promote efficient flocculation and separation of chalcopyrite and pyrite from quartz minerals; however, more research on the mixed systems is required.

\section{Conclusions}

The performance of SiCNF was evaluated on flocculation of ultrafine mineral particles of chalcopyrite, pyrite, and quartz, separately in single mineral systems. The flocculation promoted by $\mathrm{SiCNF}$ was then evaluated via the turbidity removal in the dispersion of separate fine particles.

The efficiency of turbidity removal was observed to be always better for the chalcopyrite and pyrite suspensions compared with the quartz suspension both with SiCNF and the reference flocculation agent, indicating a more efficient flocculation of sulfide minerals. Higher concentrations of SiCNF were required to achieve results similar to those 
obtained using a commercial polyacrylamide in terms of reduced turbidity and floc size. However, SiCNF represents a valuable environmentally friendly alternative, and the results indicate the use of SiCNF as a flocculant for sulfide minerals separation is promising.

The specific interaction between SiCNF and pyrite or chalcopyrite led to the flocculation of sulfide minerals, which was presumably mediated by the bridging mechanism. This mechanism was supported by the fast flocculation rate and the relatively open aggregates.

The selectivity of SiCNF on flocculation of ultrafine mineral particles of chalcopyrite, pyrite, and quartz, in mixed mineral systems must be further analyzed and corroborated.

Acknowledgements The authors thank all the laboratory technicians from the IFAD, TU Clausthal, and Fiber and Particle Engineering, University of Oulu. Special acknowledgment for the contributions of Tamara Schueler and Victor Carvalho in the mineral sample preparation, Petra Sommer in the ICP-OES analysis, Juliana Antoniasi in the XRD analysis, Sarah Tuchtfeld and Jarno Karvonen in the particle-size measurements. The research leading to these results received funding from the Horizon 2020 Program of the European Union under Grant Agreement No. 812580 (MSCA-ETN SULTAN). This publication reflects only the view of the authors, the European Union is exempted from any liability. Project website: http://etn-sultan.eu/.

Funding Open Access funding enabled and organized by Projekt DEAL.

\section{Declarations}

Conflicts of interest On behalf of all authors, the corresponding author states that there is no conflict of interest.

Open Access This article is licensed under a Creative Commons Attribution 4.0 International License, which permits use, sharing, adaptation, distribution and reproduction in any medium or format, as long as you give appropriate credit to the original author(s) and the source, provide a link to the Creative Commons licence, and indicate if changes were made. The images or other third party material in this article are included in the article's Creative Commons licence, unless indicated otherwise in a credit line to the material. If material is not included in the article's Creative Commons licence and your intended use is not permitted by statutory regulation or exceeds the permitted use, you will need to obtain permission directly from the copyright holder. To view a copy of this licence, visit http://creativecommons.org/licenses/by/4.0/.

\section{References}

1. Bulatovic SM (2007) Dispersion, coagulation and flocculation. In: Bulatovic SM (ed) Handbook of flotation reagents. Elsevier, Amsterdam, pp 215-233

2. Wills BA, Finch JA (2016) Froth flotation. In: Wills' mineral processing technology. Elsevier, Amsterdam, pp 265-380

3. Attia YA-HI (1974) Selective flocculation of copper minerals. Imperial College of Science and Technology, London

4. Somasundaran P, Runkana V (2000) Selective flocculation of fines. Trans Nonferrous Met Soc China 10:8-11
5. Aruna VAJ, Shende SM (2006) Floc-flotation of chalcopyrite from a low grade $\mathrm{Cu}-\mathrm{Zn}$ ore. NML, Chennai, pp 265-269

6. Friend JP, Kitchener JA (1973) Some physico—chemical aspects of the separation of finely-divided minerals by selective flocculation. Chem Eng Sci 28:1071-1080. https://doi.org/10.1016/00092509(73)80010-7

7. Mweene L, Subramanian S (2018) Selective dispersion-flocculation and flotation studies on a siliceous copper ore. Physicochem Probl Miner Process 54:1282-1291. https://doi.org/10.5277/ ppmp18186

8. Ng WS, Connal LA, Forbes E, Franks GV (2016) Xanthate-functional temperature-responsive polymers as selective flocculants and collectors for fines recovery. Miner Eng 96-97:73-82. https:// doi.org/10.1016/j.mineng.2016.05.013

9. Somasundaran P (1978) Selective flocculation of fines. In: The physical chemistry of mineral-reagent interactions in sulfide flotation. US Bureau of Mines, pp 150-167

10. Attia YA (1982) Fine particle separation by selective flocculation. Sep Sci Technol 17:485-493. https://doi.org/10.1080/0149639820 8068553

11. Attia YA, Moudgil BM, Chander S (1988) Interfacial phenomena in biotechnology and materials processing: proceedings of the international symposium on interfacial phenomena in biotechnology and materials processing, 3-7 August 1987. Elsevier, Boston

12. Attia YA, Kitchener JA (1975) Development of complexing polymers for the selective flocculation of copper minerals. In: 11th International mineral processing congress, Cagliara, Italy

13. Drzymala J, Fuerstenau D (1981) Selective flocculation of hematite in the hematite-quartz-ferric ion-polyacrylic acid system. Part 1, activation and deactivation of quartz. Int J Miner Process 8:265-277. https://doi.org/10.1016/0301-7516(81)90016-8

14. Moudgil BM, Mathur S, Prakash TS (1997) Advances in selective flocculation technology for solid-solid separations. Kona 15:5-20

15. Pradip, Moudgil B (1991) Selective flocculation of tribasic calcium phosphate from mixtures with quartz using polyacrylic acid flocculant. Int J Miner Process 32:271-281. https://doi.org/10. 1016/0301-7516(91)90073-R

16. Yarar B, Kitchener JA (1970) Selective flocculation of minerals. Pt. 1. basic principles. Pt. 2. Experimental investigation of quartz, calcite, and galena. Trans Inst Min Met 79:23-33

17. Mandre NR, Panigrahi D (1997) Studies on selective flocculation of complex sulphides using cellulose xanthate. Int J Miner Process 50(3): 177

18. Bulatovic SM (1999) Use of organic polymers in the flotation of polymetallic ores: a review. Miner Eng 12:341-354. https://doi. org/10.1016/S0892-6875(99)00015-1

19. Sresty GC, Somasundaran P (1980) Selective flocculation of synthetic mineral mixtures using modified polymers. Int J Miner Process 6:303-320. https://doi.org/10.1016/0301-7516(80)90027-7

20. Vergouw JM, Difeo A, Xu Z, Finch JA (1998) An agglomeration study of sulphide minerals using zeta-potential and settling rate. Part 1: pyrite and galena. Miner Eng 11:159-169. https://doi.org/ 10.1016/S0892-6875(97)00148-9

21. Vergouw JM, Difeo A, Xu Z, Finch JA (1998) An agglomeration study of sulphide minerals using zeta potential and settling rate. Part II: sphalerite/pyrite and sphalerite/galena. Miner Eng 11:605-614. https://doi.org/10.1016/S0892-6875(98)00045-4

22. Vajihinejad V, Gumfekar SP, Bazoubandi B et al (2019) Water soluble polymer flocculants: synthesis, characterization, and performance assessment. Macromol Mater Eng 304:1800526. https:// doi.org/10.1002/mame.201800526

23. Brostow W, Hagg Lobland H, Pal S, Singh R (2009) Polymeric flocculants for wastewater and industrial effluent treatment. J Mater Educ 31:157-166

24. Ge W, Li H, Ren Y et al (2015) Flocculation of pyrite fines in aqueous suspensions with corn starch to eliminate mechanical 
entrainment in flotation. Minerals 5:654-664. https://doi.org/10. 3390/min5040515

25. Salehizadeh H, Yan N, Farnood R (2018) Recent advances in polysaccharide bio-based flocculants. Biotechnol Adv 36:92-119. https://doi.org/10.1016/j.biotechadv.2017.10.002

26. Huan S, Ago M, Borghei M, Rojas OJ (2018) Nanocelluloses at the oil-water interface: emulsions toward function and material development. In: Cellulose science and technology. Wiley, Hoboken, pp 393-421

27. Kedzior SA, Gabriel VA, Dubé MA, Cranston ED (2020) Nanocellulose in emulsions and heterogeneous water-based polymer systems: a review. Adv Mater. https://doi.org/10.1002/adma. 202002404

28. Liimatainen H, Sirviö J, Sundman O et al (2012) Use of nanoparticular and soluble anionic celluloses in coagulation-flocculation treatment of kaolin suspension. Water Res 46:2159-2166. https:// doi.org/10.1016/j.watres.2012.01.035

29. Sirviö J, Honka A, Liimatainen H et al (2011) Synthesis of highly cationic water-soluble cellulose derivative and its potential as novel biopolymeric flocculation agent. Carbohydr Polym 86:266-270. https://doi.org/10.1016/j.carbpol.2011.04.046

30. Suopajärvi T, Liimatainen H, Hormi O, Niinimäki J (2013) Coagulation-flocculation treatment of municipal wastewater based on anionized nanocelluloses. Chem Eng J 231:59-67. https://doi.org/ 10.1016/j.cej.2013.07.010

31. Kemppainen K, Suopajärvi T, Laitinen O et al (2016) Flocculation of fine hematite and quartz suspensions with anionic cellulose nanofibers. Chem Eng Sci 148:256-266. https://doi.org/10.1016/j. ces.2016.04.014

32. Laitinen O, Kemppainen K, Ämmälä A et al (2014) Use of chemically modified nanocelluloses in flotation of hematite and quartz. Ind Eng Chem Res 53:20092-20098. https://doi.org/10.1021/ ie $503415 \mathrm{t}$

33. Adkins SJ, Pearse MJ (1992) The influences of collector chemistry on kinetics and selectivity in base-metal sulphide flotation. Miner Eng 5:295-310. https://doi.org/10.1016/0892-6875(92)90212-R

34. Avotins PV, Wang SS, Nagaraj D (1994) Recent advances in sulfide collector development. In: Reagents for better metallurgy. Society for Mining Metallurgy \& Exploration, pp 47-56

35. Wightman EM, Grano SR, Ralston J (2000) Selectivity in the polymer assisted separation of galena from quartz by flotation. Miner Eng 13:843-856. https://doi.org/10.1016/S0892-6875(00) 00073-X

36. Elizondo-Álvarez MA, Uribe-Salas A, Bello-Teodoro S (2021) Chemical stability of xanthates, dithiophosphinates and hydroxamic acids in aqueous solutions and their environmental implications. Ecotoxicol Environ Saf 207:111509. https://doi.org/ 10.1016/j.ecoenv.2020.111509

37. Singh K, Ihlenfeld C, Oates C et al (2011) Developing a screening method for the evaluation of environmental and human health risks of synthetic chemicals in the mining industry. Int J Miner Process 101:1-20. https://doi.org/10.1016/j.minpro.2011.07.014

38. Xu Y, Lay JP, Korte F (1988) Fate and effects of xanthates in laboratory freshwater systems. Bull Environ Contam Toxicol 41:683-689. https://doi.org/10.1007/BF02021019

39. Baudet G, Moriot M (1978) Synthesis and characterization of selective flocculants based on xanthate derivatives of cellulose or amylose. Ind Min Miner 1:19-35

40. Termes SC, Wilfong RL, Richardson PE (1983) Flocculation of sulfide mineral fines by insoluble cross-linked starch xanthate. U.S. Department of the Interior, Bureau of Mines

41. Boulton A, Fornasiero D, Ralston J (2001) Selective depression of pyrite with polyacrylamide polymers. Int J Miner Process 61:13-22. https://doi.org/10.1016/S0301-7516(00)00024-7
42. Sirviö JA, Visanko M, Liimatainen H (2015) Deep eutectic solvent system based on choline chloride-urea as a pre-treatment for nanofibrillation of wood cellulose. Green Chem 17:3401-3406

43. Rath RK, Subramanian S, Sivanandam V, Pradeep T (2001) Studies on the interaction of guar gum with chalcopyrite. Can Metall Q 40:1-11. https://doi.org/10.1179/cmq.2001.40.1.1

44. Reyes-Bozo L, Escudey M, Vyhmeister E et al (2015) Adsorption of biosolids and their main components on chalcopyrite, molybdenite and pyrite: zeta potential and FTIR spectroscopy studies. Miner Eng 78:128-135. https://doi.org/10.1016/j.mineng.2015. 04.021

45. Dhar P, Thornhill M, Kota H (2019) Investigation of copper recovery from a new copper ore deposit (Nussir) in northern Norway: dithiophosphates and xanthate-dithiophosphate blend as collectors. Minerals 9:146. https://doi.org/10.3390/min9030146

46. Mitchell TK, Nguyen AV, Evans GM (2005) Heterocoagulation of chalcopyrite and pyrite minerals in flotation separation. Adv Colloid Interface Sci 114-115:227-237. https://doi.org/10.1016/j. cis.2004.08.009

47. Somasundaran P (1986) Advances in mineral processing. Society of Mining Engineers, Englewood

48. Liang L, Wang L, Nguyen AV, Xie G (2017) Heterocoagulation of alumina and quartz studied by zeta potential distribution and particle size distribution measurements. Powder Technol 309:1-12. https://doi.org/10.1016/j.powtec.2016.12.054

49. Yukselen-Aksoy Y, Kaya A (2011) A study of factors affecting on the zeta potential of kaolinite and quartz powder. Environ Earth Sci 62:697-705. https://doi.org/10.1007/ s12665-010-0556-9

50. Wu C, Wang L, Harbottle D et al (2015) Studying bubble-particle interactions by zeta potential distribution analysis. J Colloid Interface Sci 449:399-408. https://doi.org/10.1016/j.jcis.2015.01. 040

51. Xu D, Ametov I, Grano SR (2012) Quantifying rheological and fine particle attachment contributions to coarse particle recovery in flotation. Miner Eng 39:89-98. https://doi.org/10.1016/j. mineng.2012.07.003

52. Patra P, Natarajan KA (2006) Surface chemical studies on selective separation of pyrite and galena in the presence of bacterial cells and metabolic products of Paenibacillus polymyxa. J Colloid Interface Sci 298:720-729. https://doi.org/10.1016/j.jcis.2006.01. 017

53. Reyes-Bozo L, Herrera-Urbina R, Escudey M et al (2011) Role of biosolids on hydrophobic properties of sulfide ores. Int $\mathrm{J}$ Miner Process 100:124-129. https://doi.org/10.1016/j.minpro.2011.05. 009

54. Liu JC, Huang CP (1992) Electrokinetic characteristics of some metal sulfide-water interfaces. Langmuir 8:1851-1856. https:// doi.org/10.1021/la00043a027

55. Andresen M, Johansson L-S, Tanem BS, Stenius P (2006) Properties and characterization of hydrophobized microfibrillated cellulose. Cellulose 13:665-677. https://doi.org/10.1007/ s10570-006-9072-1

56. Geng B, Wang H, Wu S et al (2017) Surface-tailored nanocellulose aerogels with thiol-functional moieties for highly efficient and selective removal of $\mathrm{Hg}$ (II) ions from water. ACS Sustain Chem Eng 5:11715-11726. https://doi.org/10.1021/acssuschem eng.7b03188

57. Goussé C, Chanzy H, Excoffier G et al (2002) Stable suspensions of partially silylated cellulose whiskers dispersed in organic solvents. Polymer 43:2645-2651. https://doi.org/10.1016/S00323861(02)00051-4

58. Indarti E, Marwan WWD (2020) Effect of temperature on the silylation of nanocrystalline cellulose from oil palm empty fruit bunch with 3-aminopropyltriethoxysilane. IOP Conf Ser Earth 
Environ Sci 425:012065. https://doi.org/10.1088/1755-1315/ 425/1/012065

59. Khanjanzadeh H, Behrooz R, Bahramifar N et al (2018) Surface chemical functionalization of cellulose nanocrystals by 3 -aminopropyltriethoxysilane. Int J Biol Macromol 106:1288-1296. https://doi.org/10.1016/j.ijbiomac.2017.08.136

60. Takagai Y, Shibata A, Kiyokawa S, Takase T (2011) Synthesis and evaluation of different thio-modified cellulose resins for the removal of mercury (II) ion from highly acidic aqueous solutions. J Colloid Interface Sci 353:593-597. https://doi.org/10.1016/j.jcis. 2010.09.070

61. Thakur MK, Gupta RK, Thakur VK (2014) Surface modification of cellulose using silane coupling agent. Carbohydr Polym 111:849-855. https://doi.org/10.1016/j.carbpol.2014.05.041

62. Morantes D, Muñoz E, Kam D, Shoseyov O (2019) Highly charged cellulose nanocrystals applied as a water treatment flocculent. Nanomaterials 9:272. https://doi.org/10.3390/nano9020272

63. Grenda K, Gamelas JAF, Arnold J et al (2020) Evaluation of anionic and cationic pulp-based flocculants with diverse lignin contents for application in effluent treatment from the textile industry: flocculation monitoring. Front Chem. https://doi.org/10.3389/ fchem.2020.00005

64. Rutledge J (2016) Fundamental surface chemistry and froth flotation behavior using quebracho tannins. Thesis, Colorado School of Mines

65. Nasser M, James AE (2006) The effect of polyacrylamide charge density and molecular weight on the flocculation and sedimentation behaviour of kaolinite suspensions. Sep Purif Technol 52:241-252. https://doi.org/10.1016/j.seppur.2006.04.005

66. Bolto B, Gregory J (2007) Organic polyelectrolytes in water treatment. Water Res 41:2301-2324. https://doi.org/10.1016/j.watres. 2007.03.012

67. Tripathy T, De B (2006) Flocculation: a new way to treat the waste water. J Phys Sci 10:93-127

Publisher's Note Springer Nature remains neutral with regard to jurisdictional claims in published maps and institutional affiliations. 